\title{
The Affective Politics of the Sustainable Development Goals: Partnership, Capacity-Building, and Big Data
}

\author{
Please seek author permission to cite
}

Clive Gabay and Suzan Ilcan

\section{Published in: Globalizations}

Clive Gabay

School of Politics and International Relations, Queen Mary University of London, Mile End Road, London, E1 4NS

UK

Suzan Ilcan,

Department of Sociology and Legal Studies, University of Waterloo

200 University Ave W,

Waterloo, ON N2L 3G1,

Canada

Clive Gabay is a Senior Lecturer in the School of Politics and International Relations at Queen Mary University of London. He has interests in the political sociology of international development, and the historical sociology of Whiteness, as refracted through the public production of ideas about Africa in $20^{\text {th }}$ and $21^{\text {st }}$ Century Britain. His most recent book, Exploring an African Civil Society: Development and Democracy in Malawi, 1994-2014 was published by Lexington Books in 2016.

Suzan Ilcan is Professor of Sociology in the Department of Sociology and Legal Studies at the University of Waterloo and the Balsillie School of International Affairs. Her research focuses on international development and humanitarian aid, migration and refugee studies, and citizenship and social justice. She is the author of Longing in Belonging: The Cultural Politics of Settlement (Praeger), co-author of Issues in Social Justice: Citizenship and Transnational Struggles (Oxford UP) and Governing the Poor: Exercises of Poverty Reduction, Practices of Aid (McGill-Queen's UP), and editor of Mobilities, Knowledge, and Social Justice (McGill-Queen's UP).

\footnotetext{
Abstract

In this article we argue that whilst international studies broadly construed has benefitted in recent years from a turn to theories of affect, a notable absentee in this regard has been critical accounts of international development. We suggest that theories of affect have much to contribute to an understanding of a set of international policies and practices that seek to remake individual and collective capacities to act in the pursuit of 'development'. The article therefore sets out to briefly establish a genealogy of affect written through post World War Two international development policies, before laying out three areas where contemporary international development policy, in the form of the United Nations Sustainable development Goals, manifests most notably. These three areas are (i) Partnership; (ii) Capacity Building
} 
and (iii) Big Data. We provide evidence to illustrate how affect works to create embodied resonances and intensities that circulate socially between and through bodies and create new intimate connections, imaginations, and certain kinds of citizens, and in so doing creates political enclosures, but also opportunities to produce 'counter-affects' and other-form ways of being and living.

Keywords: Affect; Sustainable Development Goals; Partnership; Capacity-Building; Big Data

\section{Introduction}

In recent years there has been an increasing amount of scholarship concerned with Affect and International Studies. For the most part, this scholarship has focussed on two related topics:

a) The epistemological challenge represented by the foregrounding of emotion in the study of international relations;

b) The political production of affective communities driven by a variety of different emotions i.e. fear, hope, love, etc.

Two gaps remain in this 'turn to affect'. Firstly, the prevailing literature on affect and international studies remains relatively narrow, defining affect in relation to the realm of emotions, rather than affect understood more broadly as "the capacities to act and be acted upon" (Gregg and Seigworth, 2010: p.1). Secondly, this is a literature which has largely been confined to the deconstruction of IR as a disciplinary paradigm, and/or critical security studies. Whilst sympathetic to the critique of IR which holds that 'few realms are more infused with emotion' (Hutchison and Bleiker, 2014: 494), i.e. fear, aggression, etc., we also believe that theories of affect may have a lot more to offer for a more grounded study of the international. Additionally, in this paper we argue that as much as the emotional has begun to penetrate into important IR debates, one surprising area where there is a lack of scholarship concerning affect is international development. This, we argue, is a surprising gap in the literature given the broadly affective nature of historical and contemporary development policy, which has sought to not simply therapise (Chatterjee, 2004: 36-38) or depoliticise (Escobar, 1995: 88) the subjects of development ('the poor', 'people living in poverty', etc.), but also to actively and affectively remake individuals in the image and imagination of prevailing development orthodoxy. As such, in this article, we build on scholarship that explores affect on a broader terrain than that of simply emotion, to define affect as a 'force' (see also Lofgren 2014; Gregg and Seigworth, 2010; Mankekar and Gupta 2016) comprised of embodied resonances and intensities that circulate socially between and through bodies to create new intimate connections, imaginations, and certain kinds of citizens, be they entrepreneurial, fearful, or otherwise.

The paper is divided into three sections. The first section introduces the relationship between affect and IR which serves as a backdrop to the following section that situates the role of affective politics in the international development field. This second section provides a genealogy of affect in post-World War Two modernisation theory-inflected development orthodoxy, which constructed sets of people-as-objects, in need of development. The third and main section analyzes a range of affective practices that have opened up since the turn of the century, characterised by the United Nations Millennium Development Goals (MDGs). We emphasize that these practices have been harnessed in the transition to the Sustainable Development Goals era where the affective politics of partnership, capacity-building, and big data are particularly prominent components of the SDG framework. 


\section{(i) IR and an 'Affective Turn'}

In this section we will briefly highlight the two main ways in which affect has become prominent in IR scholarship, both of which cohere around affect-as-emotion. Whilst we broadly sympathise with the claims made by the scholars we consider below, we will further argue that deploying affect-as-emotion limits the ways in which affect can contribute to IR and International Studies scholarship.

In 2014 the journal International Theory published a special forum on emotions and world politics. This collection of commentaries is broadly representative of the macro-level concerns which have recently been animating the turn to affect in IR. In sum, the contributing scholars to this forum take a more or less collective view that a consideration of emotion can perform two functions. First, it can reveal how collective norms are generated and what they do. Neta Crawford for instance seeks to explain how states internalise particular emotional predispositions, and the kinds of politics these make possible and impossible (2014), whilst Mattern writes of her conviction that there is a relationship between 'emotion, collectivities, and action' (2014: 589). The second core function which emerges through this collection is that a focus on emotion can contribute to a deconstruction of IR as a discipline of universal claims which are themselves fundamentally emotional (i.e. all states act selfishly because all people are fundamentally selfish), in order to open up a vista of multiple collective emotional affinities, 'multiple co-existing emotional worlds...the multiple legacies of thinking, doing, being, and relating that are normally not appreciated in Eurocentric scholarship' (Ling, 2014: 579). Recognising the inter-constitutionality of these co-existing emotional worlds, Ling further argues that 'from such mutual embeddedness, dialogue across multiple worlds of emotions can facilitate understanding and even solve conflicts in a way a dominant single narrative cannot' (Ibid: 582).

A more grounded approach to affect and IR can be found amongst scholarship in critical security studies, where various contributions have highlighted the place of emotions and affective ties in constructing communities of fear or hope, with implications for communal and national identity and policy-making (for instance, Hutchinson, 2010; 2013; Åhälla and Gregory 2013; 2015). Others have explored the place of emotions in contributing to security policies and the securitisation of certain issues (for instance: Reinke de Buitragoa, 2016; Van Rythoven, 2015). ${ }^{1}$ Like the more macro-level literature considered above however, in the main this security-studies scholarship refrains from expanding the scope of affect theory from the strictly emotional to explore issues of how capacities to be, know and act are created through sometimes social, sometimes non-social relations (for an exception see: Anderson and Addey, 2011).

Other scholarship on affect underscores the relationship between affect and politics in important ways. For example, a more grounded approach to affect can be identified in the work on the affected dimensions of geopolitics and everyday life, including those concerned with physical sites of geopolitics (Pain and Smith 2008) and cultural analysis (Lofgren 2014; Massumi 1995). Nigel Thrift (2000), for example, has called attention to the everyday workings of geopower by attending to objects, to the human body, and to matters of affect, as opposed to the privileging of texts and images. In this context, Squire (2015: 146) notes that such studies emphasize the importance of moving beyond a representational/nonrepresentational divide. In the field of cultural studies, and more specifically non-

\footnotetext{
${ }^{1}$ There is a related literature on affective ties in the social movements literature. See for instance Currans, Schuler and Willougby-Herard, 2012.
} 
representational theory, Lofgren (2014: 78) emphasizes that a focus on the "how" rather than the "why" of social action pays less attention to codes and representations and more to everyday practices, sensibilities, and feelings. The latter can lead to understanding the making and remaking of everyday life, and the ways that objects, people, feelings, sensibilities or activities co-exist.

A broader definition of affect that is commonly applied in IR scholarship thus sees affect as that collection of visceral forces that operate 'beneath, alongside, or generally other than conscious knowing', which drive humans and non-humans 'toward movement, toward thought and extension' or can suspend, or leave us 'overwhelmed by the world's apparent intractability' (Gregg and Seigworth, 2010: 1). As social beings, we are always immersed in and among these forces, which can act as much as blockages for certain and alternative ways of being and acting, as they can act as invitations to do the same. In this regard, viewing affects as forces enables researchers to explore the in-betweenness of human actors and of humans and objects (see Lofgren 2014:74). As Gregg and Seigworth (2010) emphasize, affect is about reactions and communications which can compel us towards movement or thought - a fleeting mood, an unexpected sensibility, a clambering impatience or anxiety. Similarly, Ngai (2005; see Vukov no date) considers affect as a less subjective, a-signifying set of embodied resonances, sensations, and intensities that circulate socially between and through bodies and accumulate to form a kind of backdrop, tone, or climate. In terms of the relationship between intensities and affect, Mankekar and Gupta (2016: 24) suggest that affect is a series of intensities "that circulate between bodies and objects and between and across bodies", and that can transform experiences of time and temporality and landscapes of close encounters.

As such we can see that affect is not simply reducible to observable emotions but to the whole range of submerged and non-conscious, stimulated feelings which might facilitate particular actions and practices. For Massumi, affect is neither passive, precisely because it induces movement, but it is also not active, because it is not-yet-activity, and as such cannot be operated and directed (Massumi, 1995). Affect is thus known by its effects, a reason perhaps for Mattern's stark admittance that, despite being convinced of the place of emotions as an explanatory factor in world politics, '...the best work on emotion collapses without much pressure. Even my own work collapses' (2014: 586). And yet this is once again perhaps because observed emotion is not the same as unobserved affect, and a theory of emotion is not really the end point, because emotion itself is a product of affect.

So while affect and emotion are of course related, affect, unlike emotion:

...cannot be understood solely in terms of a symptom of ideology, mode of production and emotional manipulation... a set of practices that manipulate subjects and their emotions as ways of reproducing the conditions and structures of production. By contrast to subjects' emotion, affect is apparent to the body in ways apart from signifying form and structure. Affect is intelligence that inheres in what is sensed, but has not been signified in knowable forms and determinate structural positions (Dia Costa: 2016: 4).

Emotion then, 'is the articulation of affect and ideology...the ideological attempt to make sense of some affective productions' (Grossberg, 2010: 316). Turning to how an affect paradigm might be applied to an analysis of international development orthodoxy, it would be necessary to identify the affective content of this orthodoxy, and its embodied and visceral 
effects. To be clear though, this is not the same as drawing straight lines of causation between international development orthodoxy and the embodied expressions of developmental subjects. Rather, it is to seek to understand the affective content of this orthodoxy, and then to trace its effects, however they manifest, and with whatever else they interpolate, in their full range of unexpected, contradictory and/or self-reinforcing expressions. This is an agenda that moves beyond what we are able to address in this one article, but we hope that along with others this is an agenda we will be able to move forward with as the contemporary paradigm of the Sustainable Development Goals unfolds in subsequent years. What we offer here then is a starting point or platform upon which such an agenda might stand. To begin with, we next offer a brief genealogy of the affective politics of post-World War Two international development orthodoxy.

\section{(ii) Towards a brief genealogy of the affective politics of Post World War Two Development Orthodoxy}

There is no significant literature which brings affect theory to bear on the subject of International Development. This is surprising given the historical record of development policy and practice, which, in ever bolder terms, has sought to construct 'developed' subjects, with new feelings, capacities and practices. In this section we seek to map out this history of affective politics.

\section{Post-War Modernisation Theory}

Modernisation Theory, most popularly associated with North American social scientists and economists such as Walt Rostow, heavily influenced post-World War Two development orthodoxy. Briefly, the theory contended that development was synonymous with capitalism, liberal-democratic norms and a Weberian sensibility towards work, savings and consumption. There are well-rehearsed critiques of both the ideological structure upon which modernisation theory stands and the post-war development orthodoxy modernisation theory spawned. Whilst Kiely (1995: Chapter 3) for instance brings our attention to the contradictions which beset modernisation theory (most notably that it contains no account whatsoever of the centrality of empire and appropriation to modern capitalist development in the West), and Escobar (1995) to the relationship between post-war development discourse, racism and neoimperialism, neither of these broadly representative lines of critical scholarship pay attention to the affective content of post-war development orthodoxy. In other words, we are not left with an account of either the ways in which post-war development orthodoxy sought to create capacities to act amongst object populations (transforming these objects into particular subject-categories), nor how these affective agendas brought counter-affects and countercapacities into play which acted as more or less explicitly resistant blockages to the post-war development project.

Whilst it is beyond our ability here to provide more than a speculative account of such counter affects and practices, key source texts of post-war development orthodoxy provide rich detail on the kinds of affective capacities key protagonists in this process sought to build amongst what were arguably considered in these texts as the object populations of the Third World i.e. populations groups which could be manipulated and shifted to create desired macro geo-political and economic outcomes. Importantly however, these manipulations were also conceived as micro-affects, taking place at the level of the individual body and mind. Only with this rather Weberian conception of development as personal-before-social change could the broader macro-agenda be achieved. 
In their influential text The Civic Culture, Almond and Verba reflect on the factors necessary for the reproduction of Western liberal democracy in the developing world. They identify the existence of three ideal-typical political cultures: parochial cultures, subject cultures, and participant cultures. The first predominates in the Third World, where people prioritise familial and kin ties, the second in the Communist world, where the vitality of populations is at the whim of an authoritarian form of government, and the last is characteristic of the West, where people act as active citizens (Almond and Verba, 1963: 17-22). As ideal types, Almond and Verba argue that in practice even Western liberal democracies are a mixture of the three different cultures, each acting to modify each other. As a result, whilst Third World societies lack much in the way of even subject, let alone participant culture, even Western liberal democracies exist at the intersection of several, sometimes contending impulses, whereby the individual in these societies is "not the active citizen: he is the potentially active citizen" (Ibid: 347, emphasis added). Pessimistic about the prospects of Third World societies to even reach this point (due to the relative lack of time given over for their development), it is within this gap, between the ideal-type of the active citizen, and the individual-aspotentially active, that post-war international development orthodoxy sits as it attempts to affect capacities amongst the individual objects of Third World (not-yet) societies. Rostow, more implicitly, also engages in this 'not-yet' analysis that development orthodoxy seeks to address. Although generally more renowned for his 1960 work The Stages of Economic Growth: A Non-Communist Manifesto, it was in later works where the more affective content of his analysis emerged more explicitly. It is a particular set of affective practices - religion and magic - which for instance holds Third World societies back from their developmental and democratic potentials (1971: 31). Once again, it is a different set of affective capacities, ones which are "more recognizable" (Ibid: 33) which could set Third World Societies on the path to active participative democracy.

But where Almond and Verba are pessimistic, Rostow, possibly because he has actually thought to travel in and study the aspects of the societies of which he talks (Almond and Verba's case studies for The Civic Culture were the UK, US, Italy, West Germany and Mexico), writes with great optimism about the prospects of democratic development in these societies. And his optimism is based precisely on a visceral projection of affective commitment to the ideals of participative democracy. It is the "dignity and conviction" with which people wait to vote; the "shrewd and passionate faces" of the people who have committed to make a better life for themselves and their families (Ibid: 301). Such visceral expressions are taken to indicate the affective capacities and emotional desires of Third World objects to become subjects, to leap from the potentially active to the active citizen. . Another seminal text in post-War development orthodoxy, President Harry Truman's second inaugural address in $1949^{2}$, lays the groundwork for this leap to occur, for the building of the affective capacities of developmental objects-into-subjects. On the one hand, Truman relates that Third World objects live in misery, their lives inadequate. They are victims, and their lives are primitive and stagnant. In Truman's words then, the mission of post-war development orthodoxy must be to 'supply the vitalizing force', and to provoke objects into agents of 'triumphant action', warriors against 'their ancient enemies: hunger, misery and despair'.

\footnotetext{
${ }^{2}$ Available at: https://www.trumanlibrary.org/whistlestop/50yr_archive/inagural20jan1949.htm accessed on
} 9th June 2016. The italicised words which follow are lifted directly from the text of the speech 
Escobar has very methodically critiqued the racialised aspects of Truman's speech, the ways in which it asserts a passive, 'undeveloped' world which requires Western animation (Escobar, 1995: Chapter Two). The point we would like to dwell on here is this animative element. For it is within this that we find post-War development's affective agenda, an agenda which seeks to animate the capacities of Third world objects, and turn them into active subjects. These populations are subjects in the sense that they are subjected to a particular political and economic orthodoxy, and active in the sense that it is the sincere aim of this orthodoxy to inculcate the auto-generative capacities required to sustain capitalism and liberal democracy amongst third world object populations.

This is the context in which we understand Truman's speech. The 'vitalizing force' of which he speaks quite clearly has affective implications. Contradicting itself however, the kind of state-led, infrastructural development characteristic of this era, and the kinds of authoritarian regimes that this orthodoxy sustained ${ }^{3}$, directly counteracted the affective spirit of both modernisation theory's and President Truman's social and civilisational prescriptions. The suppression of its affective content continued through into the next phase of development orthodoxy, the era of structural adjustment. Concerned with reorienting development away from the state, the policy of structural adjustment veered to the market understood in abstract, non-human terms. Although this was the overriding focus of the period, there was, as in the previous period, nonetheless an affective agenda at play, and so although critics of institutions like the World Bank in this period accused it of dehumanising and technocratising development (I.e. Ferguson, 2007: 69-88; Hulme, 2010: 29), we seek here to highlight the affective components of the structural adjustment period.

\section{From Structural Adjustment to Human Development}

In this section we seek to treat what are often taken to be two distinct periods in development orthodoxy as one. Whilst there are those who see significance in the transition away from the economistic structural adjustment policies (SAPs) of the 1980s and early 1990s towards the more human development-oriented and 'good governance' policies of the late 1990s and 2000s (see for instance Hulme and Fukuda Parr, 2007), we tend to share the sentiments of James Ferguson, who has argued that the World Bank's expansion of its modus operandi from finance ministries to ministries of health or education in the 1990s did not represent a meaningful transition in the aims of Bank policies, which remained deregulatory and exportoriented, and sought improvements in health and education as technical inputs to that end (Ferguson, 2007: 69-88. See also Harrison, 2004).

However, both supporters and critics of this supposed transition overlook the fact that there was always an element of affective engineering at play in the SAPs approach that necessitated a non-state, and ostensibly non-market focus, and that provided a bridge with what was to follow in the 1990s and 2000s under the umbrella of the Human Development agenda, or the 'post-Washington Consensus'. From a very early stage, the Bank was attuned to the micro-cultural engineering the higher rates of economic growth that structural adjustment was designed to produce required. For instance the 1980 'Berg' report (named after then head of the Bank's African Strategy Review Group, Elliot Berg), which set the SAPs agenda for Africa, advocated a position that 'Educated women, even if they do not participate in the labor force, can have a significant impact on the country's economy through

\footnotetext{
${ }^{3}$ For a detailed exploration of this relationship and its ramifications see Scott, 1999: Chapter Seven
} 
lower fertility rates, health information, and more "household production."' (World Bank, 1980: 81).

These kinds of attempts to create new, economically productive capacities amongst various population sub-groups (in this case 'women') persisted through the decade. As recognition grew that SAPs had led to economic stagnation rather than growth, delivering unto Africa a 'lost decade' (Singer, 1989), these attempts grew to a new pitch, whereby in a retrospective of Bank policy through the latter part of the 1990s and early 2000s, David Williams could write of the Bank's core mission that '[it was to] reconstruct [...] the attitudes and behaviour of individuals', based on the belief that 'it is culture rather than nature that really shapes how people act. [The Bank]... has undertaken development interventions designed to rework the habits and attitudes of persons' (Williams, 2008: 88).

In this sense the broad literature on how the good governance agenda that became prevalent in the late 1990s has been part of an agenda of undermining and emasculating the state (see, for instance, Chandhoke, 1995; Kamat, 2002; Harrison, 2004), whilst raising significant issues, has to some degree acted as a red herring. By this we mean that for all the focus on the ways in which the development orthodoxy of the 1980s, 90s and early 2000 s sought to refashion the state into a facilitator of international trade, with non-state providers acting to deliver social services, we contend that an equally important component of this agenda was to fashion the capacities of individuals and groups within the object societies of development orthodoxy. One illustrative area where individual capacity has been a major focus is in HIV/AIDS prevention, and in particular voluntary counselling and testing (VCT), which is designed to "provide people with an opportunity to learn and accept their HIV serostatus in a confidential environment with counselling and referral for ongoing emotional support and medical care" (UNAIDS, 2000: 1). In addition, counselling clients are encouraged to discuss any sexual partners who themselves might therefore be at risk of contracting HIV, and thus benefit from counselling services (Ibid: 3 ). And yet this attempt to create rational and responsible sexual subjects, who, with 'emotional support' will 'learn to accept' their status, and thus decide to self-maximise by reporting their status and those they have had sex with, has created an affective politics all of its own, namely shame, whereby uptake of VCT has been lowest in those regions with the highest HIV incidence rates (Mutale, et al, 2010: 1). This 'shaming' ethos has been in large part because of the stigma that attending VCT clinics in public view, and revealing one's health status amongst the community by reporting sexual contact with other community members, has engendered (Teklehaimanot, et al, 2016: 1). It is but one indicative example of how 'capacities to act and be acted upon' (Gregg and Seigworth, 2010: 1) are situated within a broad field of social and non-social emotional relations, including, in this case, the instigators of social norms; subjects-understood-asobjects by the aforementioned instigators; the built environment; biological viruses; communal and social networks; and so on.

Such human-centred approaches to development reached their high-point at the beginning of this century (Hulme and Fukuda-Parr, 2007) in the form of the United Nations Millennium Development Goals. The goals attracted structuralist critiques which portrayed them as fronts for global capitalist appropriation (Saith, 2006; Amin, 2006). However, whilst telling us something important about the macro-politics of international development orthodoxy, these kinds of structuralist accounts completely missed the micro and affective politics of that same orthodoxy. 
In relation to the MDGs we have both separately commented on the ways in which the goals implicitly constructed people as in need of development and as objects, and then sought to create particular capacities in order to turn them into active subjects for a particular vision of the world. For instance, Ilcan has argued that the MDGs imagined people living in object societies as passive, poorly equipped to 'fare well in a world full of risk and responsibility' (Ilcan and Phillips, 2010: 867), and thus sought to construct active subjects, 'ranging from the poor and homeless to other participants of development initiatives [...] who are increasingly made responsible to care for and govern themselves in various capacities, geographic locations and social relations' (Ibid: 856). Similarly, Gabay has argued that there is 'a logic of behaviour-change which exists within the programming of the goals' and which manifested itself in multilateral calls to 'affect private behaviour... and promote "community demand"' (Gabay, 2012: 1256).

The construction of people in need of development and as objects directly reflects the kinds of affective politics that was present in post-war modernisation theory-inflected development orthodoxy. The key difference is that turn-of-the-century development orthodoxy was much less encumbered by any prevailing Keynesian belief in the state as a vehicle for development, which had suppressed the affective politics of post-war development orthodoxy. As a result, a whole range of affective practices have opened up during the MDG era, and have been developed and finessed in the transition to the post-MDG, Sustainable Development Goal era, namely, Partnership, Capacity Building and, particularly prominent in the SDG framework, big data. The following section examines the affective politics of the SDGs.

\section{(iii) The Sustainable Development Goals}

The Sustainable Development Goals were launched in September 2015, following three years of formal inter-governmental and civil society consultation. Reflecting a much broader consultative process than that which preceded the MDGs (although one which was still constrictive and problematic - see Death and Gabay, 2015: 602), the resultant list of SDGs ran to 17 goals, compared to the 8 MDGs. Like the MDGs, each SDG comes with a subset of targets. For instance, Goal 1, 'End poverty in all its forms, everywhere', comes with a list of 7 sub-targets, with 170 sub-targets across all the goals (UN.org). The targets take into account different national settings, capacities, and levels of development while simultaneously recognizing national policies and priorities. Overall, the SDGs incorporate a commitment to reduce inequalities within and among countries, foster sustainable consumption and production patterns, and work towards the objective goal of peace, fair governance, and justice. The 17 SDGs are considered as universal, focusing on five key elements: people, planet, peace, prosperity, and partnership, although Weber, in this issue, suggests that this talk of universalism masks a very distinct neoliberal paradigm of capitalist development.

The vitalizing force of the SDGs provides a very fertile terrain upon which to explore their affective content. Rather than exploring every single target and goal however, we are limiting ourselves to only those goals and targets which directly speak to the three themes we argue have been particularly prominent in contemporary development orthodoxy, namely, partnership, capacity building, and big data. In addition to the goals and targets themselves, we also analyse relevant policy documents and speeches where these themes have been addressed. We argue that across each theme there are various affective agendas at play, including the vitalizing force of creating new intimate connections, imaginations, and entrepreneurial citizens. 


\section{a. Partnerships}

Since the 1990s, an increase in partnerships among states, international organizations, private enterprises, local governments, regional and international bodies, civil society organizations, and other actors has been shaping relations between the Global North and South as well as across cultural and material practices. These partnerships, largely invigorated by neoliberal policies and practices, are commonly promoted as working towards international cooperation, collaboration, and coordination. They span diverse social and political fields, including development and security, urban planning, migration, and modern consumption. They are, however, not apolitical processes as each partner/participant in a partnership relation has a history and diverging qualities that link it to the actions of other groups, events, landscapes, and bodies of knowledge. Scholarship on the role of partnerships in economic and social relations reveals that the emphasis on partnerships themselves work to re-align uneven relationships yet can foster unequal power relations between donor and recipient (Abrahamsen 2004). They can also work to govern certain risky and vulnerable groups (Kunz 2013: 1228), reconstitute new objects of knowledge about who, and what, is to be managed (Ilcan and Rygiel 2015), and reframe our awareness of how certain economic and social achievements can be attained. In other words, such partnerships comprise certain ways of thinking of and acting on particular groups and communities, without paying critical attention to how these partnerships can work to undermine the rights and political practices of some partners. In this way, partnerships comprise complexities of inclusion and exclusion.

The SDGs form an arena from which to examine the role of partnerships. The SDG platform calls for a renewed 'global partnership', indeed many partnerships at all levels, with all countries and stakeholders working in commonality to achieve the goals (see: https://sustainabledevelopment.un.org/sdg17). At the outset, it is understood that governments must coordinate with a broad range of global actors, such as local governments, regional and international bodies, multinational businesses, and civil society organizations. Global partnerships are thought to strengthen institutional arrangements within and across national and local governments, involving multiple ministries, departments, and government institutions. For example, 'multi-stakeholder partnerships' operating on a global scale are thought of as a necessity to complement governmental responses and leverage new resources, whether financial or in kind (see target 17.16 and 17.16). But as we discuss below, global partnerships are not only hailed as the way forward in the trajectory of sustainable development, but they are imagined as embracing responsible actors who can work together in areas ranging from information sharing and human resources to technology, strategy design, monitoring and evaluation, and volunteering (see UNV 2016; http://www.un.org/sustainabledevelopment/globalpartnerships/). In other words, global partnerships serve as the possibility of appealing to notions of social and political relationality as a means of engaging and understanding the contemporary world of development in ways which depoliticize those capacities to act that threaten the status quo of broadly capitalist and market-led development.

Under the SDG agenda, global partnerships influence the making of development objects, subjects, and practices through assembling an apparatus of potentialities, imaginations, and impacts. These partnerships are enacted through various affective relations which stimulate certain groups and spaces in particular ways and reorder our sense of how certain economic and social achievements can and should be attained. The making of partnerships can accumulate affective value through various entities, such as certain kinds of mobile, partnership-inducing entities. For example, on September 18, 2016 The UN, in collaboration with the GSMA [Global System Mobile Association] and Project Everyone, announced the 
launching of the SDGs in Action mobile phone application which provides "a global forum through which industry, governments and individual citizens can collectively realize the promise of the SDGs". ${ }^{4}$ The UN Under-Secretary-General for Communications and Public Information, Cristina Gallach, stated: "The Goals were adopted by Member States, but it is up to everyone - civil society, businesses and citizens alike - to achieve them. That is why the SDGs in Action mobile app is so timely. The app will bring the Goals closer to people and help make them more understandable and relatable to everyday life". Thus, through the vitalizing force of the SDGs in Action mobile application, global users come together in new partnership-based relations to establish an intimate connection between them and the everyday importance of the SDGs. Such an application ushers in international communication that transmits information and affect in various ways, across distances, and in a manner that makes the SDGs feel more authentic in time and space. In this regard, Nigel Thrift (2010: 294) might consider the SDGs in Action mobile application as forming part of the 'public intimacy' that is afforded by the development of new media forms which generate new kinds of appeal for contemporary consumption. In his words, public intimacy can create "new forms of body with capacity to alter to that which was previously unable to be sensed-with the corollary that certain objects can no longer be sensed-so producing the potential to generate new kinds of charms" (Thrift 2010: 295). As much as mobile applications enter our lives through a whole range of mediated platforms and forge new social and political landscapes, they are heavily implicated in the contingencies, uncertainties, and intimacies of everyday life. However, these implications are uneven. In the case of the SDGs in Action app, only those with access to smartphone technology become part of this global partnership, with its intimate connections to both other individuals, but also corporate and governmental actors. Albeit framed through the affective language of global interconnectedness, political action, for these people, also becomes an individualised and rationalised process whereby interaction with other users, data miners, data storage companies, etc. becomes mediated through individual smartphones. Conversely, by their very exclusion from this form of technopartnership, those too poor to own the appropriate technology continue to occupy a vista upon which non-individualised forms of political partnership, communality and rightsclaiming might be more unavoidable. Indeed, attempts to incorporate 'non-connected' people, understood as lacking capacities to communicate, or as the Facebook-backed 'Internet.org' puts it 'awareness', form the basis of contemporary struggles that highlight the ways in which development orthodoxy interpolates in affective fields that produce orthodoxy-reinforcing and orthodoxy-resisting partnerships ${ }^{6}$.

Returning to the SDGs, global partnerships stimulate masses of people to become primed to imagine the promises of the SDGs and primed to act, in certain groups and in certain ways. In an effort to meet the SDGs, responsible actors are alerted to the demands related to a future of sustainable development:

Urgent action is needed to mobilize, redirect and unlock the transformative power of trillions of dollars of private resources to deliver on sustainable development objectives. Long-term investments, including foreign direct investment, are needed in critical sectors, especially in developing countries. These include

\footnotetext{
${ }^{4}$ See: http://www.un.org/sustainabledevelopment/blog/2016/09/new-mobile-app-launches-todrive-action-on-sustainable-development-goals/

${ }^{5}$ See www.info.internet.org/en/approach

${ }^{6}$ See for instance the resistance to Facebook's attempts to introduce free internet access, based on a highly circumscribed list of 'partner' websites, to India.
} 
sustainable energy, infrastructure and transport, as well as information and communications technologies. The public sector will need to set a clear direction. Review and monitoring frameworks, regulations and incentive structures that enable such investments must be retooled to attract investments and reinforce sustainable development. National oversight mechanisms such as supreme audit institutions and oversight functions by legislatures should be strengthened. ${ }^{7}$

In this regard, global partnerships are enlisted for envisioning what is possible and for affecting what could be. In other words, such partnerships, as a political technology, work to change our relations with other objects and bodies in and beyond the development field. As such, they make the language and imagination of development work in particular ways and to anticipate the engagement of others, of other bodies, knowledges, and practices. Indeed, these types of partnerships - in the varieties underscoring the SDG's apparatus of rule, politicize the imagination. The role of the imagination underscoring global partnerships is a key component of affective relations and politics. On the one hand, it can contribute to the idea that certain partner groups connect to other partner groups in hopeful, generous, or benign ways in an effort achieve the SDGs. On the other hand, it can shape the conditions of possibility which in turn subjects local bodies and knowledges to the sovereignty of the scientific promises of sustainable development. As Nigel Thrift reminds us, "affect has always been a key element of politics and the subject of numerous powerful political technologies" (2004:64). For us, the political stake in understanding the affective relations of SDG-based partnerships lies in better understanding the dynamics of affective practices and how they draw on imaginations, spread, and foster masses of people to act on the basis of hope, generosity, pleasure, joy, anguish, and other visceral forces (see Gregg and Seigworth, 2010) that compel people toward movement. In the case of contemporary development orthodoxy this is a sanctioned and particular form of partnership-induced movement, based on liberal rationalities of self-maximisation, an issue we take up in the following section.

\section{b. Capacity-Building}

Since the late-colonial period, capacity-building has been integral to the ways in which capabilities or capacities (skills, training, knowledge) have been built in the international development field. Such capacities include skills-training efforts, communication technologies, and knowledge enhancement programs. For governing actors that foster such capacity-building, it is understood that these capacities are to assist certain people to both acquire particular skills and know-how, and to participate in activities and plans that lead to social and economic change. There is, however, more to capacity-building than building up certain skills, knowledge, energies, and technologies for developing economies. Research has shown that capacity-building initiatives often work to govern groups and populations by making them become self-regulating and responsible actors through their participation in the promises of market-based relations. For example, in the field of food security, capacitybuilding subjects farmers, and their ties to communities, national governments, and international organizations, to new ways of conducting themselves and connecting to others that involve the promotion of entrepreneurial communities (see O'Connor et.al, 2016; Sexsmith and McMichael, 2015). These communities link people to world markets in new ways, and their emergence provides critical insight into the diverse manner in which localities become targets from which to make certain populations more responsible for their actions and optimistic about their economic future (even if the latter especially is uneven in how it

\footnotetext{
${ }^{7}$ The Sustainable Development Goals 2016: http://www.un.org/sustainabledevelopment/globalpartnerships/ (accessed October 15, 2016).
} 
materialises). In this regard, drawing on the insights of the governmentality literature and critiques of neoliberalism, Ilcan and Phillips (2004) conceptualize capacity-building as a technology of neoliberal governance, an apparatus of rule that requires a diverse range of new rationalities that aim to "grow" institutional frameworks, enhance the skills of people, and transfer knowledge through the formation of new partnerships for international development.

In our conception, capacity-building is a line of force. It can propel certain humans and nonhuman entities forward; spread creatively, and; diverge into distinct fields. It can form links with disparate phenomena, scales, and rationalities ranging from agricultural development and poverty reduction, to state thinking. As we discuss below, capacity-building comprises affective change and specific acts, and is integral to the SDGs.

Capacity-building is a key aspect of SDG 17 ('Strengthen the means of implementation and revitalize the global partnership for sustainable development'). This Goal is sub-divided into five components: finance, ${ }^{8}$ capacity building, systemic issues, technology, and trade. ${ }^{9}$ The term capacity-building is understood to improve global support for the implementation of "targeted and effective capacity-building work in developing nations to support nationwide plans aimed at implementing all the SDGs." In this regard, global support concerns the bringing together of Governments, civil society, the private sector, the United Nations system and other actors and mobilizes available resources (see: http://www.mdgmonitor.org/sdg17sustainable-development-through-global-partnerships/). As part of this coming together, member states are "to strengthen their national institutions to complement capacity-building" (see: https://sustainabledevelopment.un.org/topics/capacity-building). Under the SDG framework, capacity-building points to the varied efforts to transform and build new collaborative ideas, assemble international information and knowledge systems, introduce new ways to foster market development and new communities in the developing world, and improve global support. For example, capacity-building is recognized in target 17.8 as a way to fully operationalize "technology and innovation capacity-building mechanism[s] for least developed countries by 2017" (see: https://sustainabledevelopment.un.org/sdg17). In target 17.9, the aim is to enhance developing countries to support national plans and implement all the SDGs (see https://sustainabledevelopment.un.org/sdg17). Similarly, among the 'Means of Implementation' listed under Chapter VI of the outcome document of the Rio +20 Conference, 'The Future We Want', capacity-building is viewed as strengthening technical and scientific cooperation. It is also acknowledged as key to the Samoa Pathway for a diverse range of areas including climate change, sustainable energy, and financing (see: https://sustainabledevelopment.un.org/topics/capacity-building). Here, capacity building, through its diverse discourses, programs, and plans, works to foster improvement, build collaboration, and harness scientific cooperation across the globe. In doing so, it comprises an affective ability to travel across vast geographical space and permeate the objectives of development politics and organization. Ben Anderson (2010: 6) reveals a similar spatial expanse of affect when he stresses that not only can affect itself be bought and sold, but 'affective capacities' can be harnessed across production processes. He gives the example of how Web 2.0 companies rely on connecting diffused desires of sociality and expression, including affective relations such as friendship and activities of browsing or linking. Likewise, Thrift demonstrates that the effectiveness of affective technologies (2007) can

\footnotetext{
${ }^{8}$ In the field of finance, for example, the Microfinance Capacity Building Initiative aims to foster market development and innovation by strengthening the ability of microfinance institutions to serve diverse groups.

${ }^{9}$ See: https://sustainabledevelopment.un.org/sdg17
} 
instill the feeling that subjects are agents of free will and volition (see Anderson 2010: 194).

Not only does capacity-building have an affective ability to travel but it can also promote change and movement in other affective ways. Through accountability and monitoring mechanisms associated with achieving the SDGs, it can instill the feeling in the partners of global development that their participation is equal to other partners, even though many partnerships are known to be unequal, hierarchical (Knight and Smith, 2004), and sometimes acrimonious (Mckeon, 2009).

At another level, capacity-building can shape the conduct of people and communities by encouraging them in certain directions, by blocking or stabilizing them, or by having individuals or community members act on their emotions and passions in ways that make productive their capacities to participate in certain kinds of international development. Amongst other things, such change can induce an optimism about the future. For example, in March 2015, the Statistical Commission agreed to establish a High-level Group for Partnership, Coordination and Capacity-building for Statistics for the 2030 Agenda for Sustainable Development. Based on the UN Economic and Security Council 2016 Session, the High-level Group is tasked with promoting national ownership of the monitoring of progress towards the 2030 Agenda and "fostering statistical capacity-building, partnerships and coordination" (UN Economic and Social Council, 2016 session, 3 June). In this regard, capacity-building can induce an 'optimism' (see Berlant 2010: 93) about the future and about one's potential role in bringing about a future that is filled with capacities that constitute and transform bodies and the relations between them, including the need for responsible actors in global partnerships. As such, it is an affective force-a visceral force that works beneath, alongside, or generally other than conscious knowing - that can serve to drive us toward movement (Seigworth and Gregg 2010: 1; Massumi 1995).

\section{c. Big Data}

One of the agendas which set the SDG discussions apart from their predecessors around the MDGs was the call for a 'data revolution'. This term was first articulated in the report by the High Level Panel of Eminent Persons (HLP, 2013: Executive Summary), which was given a mandate by UN Secretary General Ban Ki Moon to consult on a post-2015 agenda. Ban Ki Moon was a prominent supporter of this development, giving a number of speeches on the topic following the publication of the SDGs in September 2015 (See for instance Moon, 2015a; 2015b). An architecture emerged around the calls for a data revolution, driven by the United Nations Statistics Division, UNStats, but also including new actors like the Independent Expert Advisory Group on the Data Revolution for Sustainable Development, which produced a report for Ban Ki Moon called 'A World that Counts' (2014), and The Global Partnership for Sustainable Development Data, launched in the immediate aftermath of the September 2015 UN summit which ushered in the SDG era.

The various actors involved in driving the data revolution agenda broadly cohere around two main functions that this agenda should serve. First, it is asserted that better, more disaggregated data will improve decision making (Moon, 2015a), enable development interventions to reach the poorest (Higher Level Forum, 2013: 23) and help to track development indicator progress (Independent Expert Advisory Group on a Data Revolution for Sustainable Development, 2014: 6). Put together these are all interventions which are designed to improve development outcomes. Secondly, the data revolution is understood to be a way of radically democratising development, primarily at national and sub-national levels. In this sense supporters of the agenda argue that data should be used 'directly by local 
communities' as a 'meaningful vector for change at the grassroots level' (UNStats, 2015: 3), and that this will 'foster entrepreneurial innovation and empower citizens' (The Global Partnership for Sustainable Development Data, 2015). Put together, these interventions are designed to both improve development inputs, but also to achieve something more amorphous, which is to 'promote transparency and ensure accountability' (UNStats, 2015: 4), whereby data can be used by 'Civil society organisations and individuals to hold governments and companies accountable' (Independent Expert Advisory Group on a Data Revolution for Sustainable Development, 2014: 18) and 'to monitor national development strategies and results in a universally consistent way' (HLP, 2013: 24).

The affective implications of all of this might work at two different registers, one more obvious than the other. If affect 'is apparent to the body in ways apart from signifying form and structure' (Dia Costa, 2016: 4) then there are clearly more and less obvious ways in which it manifests. More obviously, for instance, the rhetoric around data presented in the various expert reports and speeches detailed above sees the 'revolutionary' aspect of data explicitly as its ability to remake bodies and communities. The first aspect of this is what Donna Harraway might call a 'god trick' (Harraway, 1988: 582), the desire to and belief in the possibility of commanding an all-knowing perspective on a particular issue. Reflecting on the limitations of previous iterations of development orthodoxy, the Independent Expert Advisory Group on a Data Revolution for Sustainable Development notes that 'It is shocking how little is known about some people...Entire groups of people and key issues remain invisible' (2014: 11-12). 'Visibility' is a key and shared term here: 'The poorest and most vulnerable people often remain invisible' argues Ban Ki Moon (Moon, 2015a); 'No one should be invisible' states UNStats (2015: 8), which advocates for the collection of data 'at the lowest possible level, by sex, age, geography, income (wealth quintiles), disability status, ethnicity, indigenous status and other vulnerable social groups, and, if and when the need arises, by other categories and groupings' (Ibid: 3).

Quite apart from the 'predictive fallacy' of big data, whereby 'all data provide oligoptic views of the world' (Kitchin, 2014: 4), what is it that these agencies wish to see? On the one hand this is unanswerable, for the data revolution is of course designed to fill a knowledge gap about the objects of development. But on the other hand there is an assumption about the kinds of people who will take up the opportunities this data revolution offers. They will be entrepreneurial, innovative and empowered (The Global Partnership for Sustainable Development Data, 2015). They will be analytically creative (UNStats, 2015: 4). They will also, and importantly, be 'citizens' (The Global Partnership for Sustainable Development Data, 2015), empowered to 'make better decisions for themselves' (Independent Expert Advisory Group on a Data Revolution for Sustainable Development, 2014: 18). This confluence of entrepreneurial citizens making 'better decisions' is arguably representative of the ways in which 'the figure of the citizen is lost' (Isin and Ruppert, 2015: 8) in discussions around big data, whereby the citizen here is summoned, rather than responded to. It is a figure "whose conduct already pertains to good civic behaviour such as participation... an already present figure" (Ibid). Actual citizenship, where an embodied subject of experience makes various rights claims, is here lost as the citizen becomes "a problem of government: how to engage, cajole, coerce, incite, invite, or broadly encourage it to inhabit forms of conduct that are already deemed to be appropriate to being a citizen" (Ibid). The SDGs apparatus illustrates how this engagement is carried out in an affective field whereby calls to innovate, connect, and be creative are designed to induce movement towards certain kinds of market-friendly subjectivity. 


\section{Conclusion}

While there exists an historical record of development policy and practice that has endeavoured to assemble 'developed' subjects with new feelings, capacities, imaginations, and practices, we have argued that there is no noteworthy literature that brings affect theory to bear on the field of international development. We have conceptualized affect as a 'force' (see also Lofgren 2014; Gregg and Seigworth 2010; Mankekar and Gupta 2016) comprised of embodied resonances and intensities that circulate socially between and through bodies and create new intimate connections, imaginations, and certain kinds of citizens. With this definition in mind, our analysis has focussed on the micro-affects of modernization theory and structural adjustment and human development orientations. The affective politics characterizing post World War II development orthodoxy, including an emphasis on animating the capacities of Third World objects and turning them into active subjects, led us to turn attention to the affective practices that have opened up since the turn of the century and which have been characterised by the United Nations MDGs. We have argued that these practices have been harnessed in the transition to the Sustainable Development Goals era where the affective politics of partnership, capacity-building, and big data are powerfully obvious components of the SDG framework. For example, we have revealed that global partnerships are enacted through affective relations that stimulate certain groups in diverse ways and reorder our sense of how economic achievements can be attained in ways that draw on the imaginations of people to act on the basis of hope and other visceral forces that compel people toward movement. Likewise, we have emphasized that the affective practices and rhetoric around big data have shown their ability to remake bodies and communities, and to foster new entrepreneurial, innovative, and empowered citizens.

Contributing to the development literature and to the scholarship on affect, our paper has demonstrated the various ways in which development discourses and practices have constituted certain populations in order to fix them, affectively, spatially, and temporally. Moreover, it has revealed that affective politics is a complex and ongoing set of processes that is 'other' oriented and animates the capacities of active subjects, and cannot exist outside political relations and histories.

\section{References}

Abrahamsen, R. 2004. The power of partnerships in Global Governance. Third World Quarterly. 25(8): 1453-1467.

Ahälla, L. and T. A. Gregory (Eds) Emotions, Politics and War (Abingdon: Routledge, 2015)

Almond, G. and S. Verba, 1963. The Civic Culture: Political Attitudes and Democracy in Five Nations (London, New York: Sage Publications)

Amin, S. 2006. 'The Millennium Development Goals: A Critique from the South' Monthly Review, March 2006 Edition, www.monthlyreview.org/0306amin.php, accessed on 22/10/2009

Anderson, B. 2010. 'Morale and the Affective Geographies of the 'War on Terror'. Cultural Geographies 17:219-236.

Anderson, B. and P. Adey, 2011. 'Affect and Security: Exercising Emergency in 'UK Civil Contingencies", Environment and Planning D: Society and Space 29 (6):1092-1109 
Berlant, L. 2010. "Cruel Optimism" in The Affect Theory Reader, eds. M. Gregg and G. Seigworth. Pp. 93-117.

Centre for the Study of Financial Innovation, 2014. 'Microfinance Banana Skins: Facing Reality' (New York: CSFI, 2014)

Chandhoke, N (1995) State and Civil Society: Explorations in Political Theory (New Delhi, Thousand Oaks, London: Sage Publications)

Crawford, N.C. 'Institutionalizing passion in world politics: fear and empathy', International Theory 6 (3), pp 535-557

Currans, E., M. Schuler and T. Willougby-Herard, 2012. 'Negotiating Treacherous Terrain: Disciplinary Power, Security Cultures, and Affective Ties in a Local Antiwar Movement' Social Justice 38(3): 60-85.

Death, C., and C. Gabay 2015. Doing Biopolitics Differently? Radical Potential in the Post2015 MDG and SDG Debates, Globalizations, 12;4

Escobar, A. (1995) Encountering Development: the Making and Unmaking of the Third World.

Gabay, C. (2012): The Millennium Development Goals and Ambitious Developmental Engineering, Third World Quarterly 33(7): 1249-1265.

Grossberg, L. (2010) 'Affect's future', in The Affect Theory Reader, ed. G. J. Seigworth and M. Gregg, Durham, NC, Duke University Press, pp. 309-338

Haraway, D. (1988). Situated Knowledges: The Science Question in Feminism and the Privilege of Partial Perspective. Feminist Studies, 14(3), 575-599.

Harrison, G. 2004. The World Bank and Africa: The Construction of Governance States (Abingdon: Routledge)

Hulme, D. (2010) Global Poverty: How Global Governance is Failing the Poor (Abingdon: Routledge)

Hulme, D. and F. Parr, S. (2007) 'The Making of the Millennium Development Goals: Human Development meets Results-based Management in an Imperfect World' Brooks World Poverty Institute Working Paper 16 (Manchester: University of Manchester Brooks World Poverty Institute)

Hutchison, E. 2010. 'Trauma and the Politics of Emotions: Constituting Identity, Security and Community after the Bali Bombing', International Relations, vol. 24 no. 1, 2010, pp. 65-86

Hutchison, E. and R. Bleiker (2014) 'Theorizing emotions in world politics' International Theory, 6, pp 491-514. 
Hutchison, E. 2013. 'Affective communities as security communities' Critical Studies on Security 1(1): 127-129.

Ilcan. S. and L. Phillips 2010. 'Developmentalities and Calculative Practices: The Millennium Development Goals' Antipode, 42(4): 844-874.

Ilcan, S. and K. Rygiel. 2015. “"Resiliency Humanitarianism': Responsibilizing Refugees through Humanitarian Emergency Governance in the Camp." International Political Sociology. 9: 333-351.

Isin, E. and E. Ruppert. 2015. Being Digital Citizens. London: Rowman \& Littlefield International.

Kamat, S. 2002. Development Hegemony: NGOs and the state in India Oxford: Oxford University Press

Kiely,R. 1995. Sociology and Development: The Impasse and Beyond (London: UCL Press)

Kitchin, R. 2014. 'Big Data, new epistemologies and paradigm shifts' Big Data \& Society, 1(1)

https://sustainabledevelopment.un.org/?menu=1300

Knight, G., and Smith, J., 2008. 'The Global Compact and Its Critics: Activism, Power Relations, and Corporate Social Responsibility' in Leatherman, J., (ed) Discipline and Punishment in Global Politics, (Basingstoke: Palgrave MacMillan), pp. 191-213

Kunz, R. (2013) Governing International Migration through Partnership. Third World Quarterly 34 (7): 1227-1246.

Ling, L.H.M. (2014), 'Decolonizing the international: towards multiple emotional worlds' International Theory, 6(3), pp 579-583

Van Rythoven, E. 'Learning to feel, learning to fear? Emotions, imaginaries, and limits in the politics of securitization' Security Dialogue, Early View, 2015

Lofgren, O. "The black box of everyday life: entanglements of stuff, affects, and activities. Cultural Analysis 13: 77-98.

Mankekar, P. and A. Gupta 2016. Intimate Encounters: Affective Labor in Call Centers. Positions 24 (1): 17-43.

Massumi, B. (1995) 'The autonomy of affect', Cultural Critique 31(2): 17-28.

Mckeon, N., The United Nations and Civil Society: Legitimating Global Governance Whose Voice? (London: Zed Books, 2009)

Mutale, W. et al. 2010. 'Home-based voluntary HIV counselling and testing found highly acceptable and to reduce inequalities' BMC Public Health 10:347.

Ngai, S. 2005. Ugly Feelings. Cambridge, Mass.: Harvard University Press. 
O'Connor, D., P. Boyle, S. Ilcan, and M. Oliver 2016. "Living with Insecurity" Food Security, Resilience, and the World Food Programme." Global Social Policy. Published Online (29 July, 1-18pp): DOI: 10.1177/1468018116658776.

Rachel, P. and S. J. Smith (eds), 2008. Fear: Critical Geopolitics and Everyday Life (Abingdon: Ashgate).

Pedwell, C. (2012) 'Affective (Self)-Transformations: Empathy, Neoliberalism and International Development', Feminist Theory 13(2), pp. 163-79.

Pedwell, C. 2014. 'Empathy, accuracy and transitional politics'. Theory, Culture and Society. (accessed on November 14, 2016): http://www.theoryculturesociety.org/carolyn-pedwell-onempathy-accuracy-and-transnational-politics/

Reinke de Buitragoa, S. 'The role of emotions in US security policy towards Iran', Global Affairs, Early View, 2016

Rostow, W.W. 1971. Politics and the Stages of Growth (Cambridge: Cambridge University Press)

Saith, A. 2006. 'From Universal Values to Millennium Development Goals: Lost in Translation.' Development and Change 37(6).

Scott, J.C. 1999. Seeing Like a State; How Certain Schemes to Improve the Human Condition have Failed (Yale: Yale University Press)

Sexsmith, K \& McMichael, P. (2015). Formulating the SDGs: Reproducing or Reimagining State-Centred Development. Globalizations 12(4), 581-596.

Singer, H.W. 1989. 'The 1980s: A Lost Decade — Development in Reverse?' in H.W. Singer and Soumitra Sharma (Eds) Growth and External Debt Management (Basingstoke: Palgrave Macmillan UK: 46-56

Squire, V. 2015. Reshaping critical geopolitics: The materialist challenge. Review of International Studies 41: 139-159.

Teklehaimanot, Hailay D., et al. 'Factors influencing the uptake of voluntary HIV counseling and testing in rural Ethiopia: a cross sectional study' BMC Public Health, 2016, 16: 239

Thrift, N. 2000. 'It's the little things', in Kenneth Dodds and David Atkinson (eds), Geopolitical Traditions: Critical Histories of a Century in Geopolitical Thought (London: Routledge, 2000), pp. 380-7.

Thrift, N. 2010. Understanding the Material Practices of Glabour in The Affect Theory Reader, eds., M. Gregg and G. Seigworth. Duke University Press.pp. 289-308.

UNAIDS (2000) Voluntary Counselling and Testing (VCT), Technical Update, available at http://data.unaids.org/Publications/IRC-pub01/jc379-vct_en.pdf, accessed on 03/11/2016

UN Millennium Project (2005), 'Report for the Secretary General', available at ttp://www.unmillenniumproject.org/reports/fullreport.htm, accessed 26 January 2012 
UNV 2016. Volunteering as Essential in Achieving Sustainable Development: UNV Responding to the 20130 Agenda. 20 April. UNV Discussion Paper.

Vukov, T. no date. Strange Moves: Speculations and Propositions on Mobility Justice.

Williams, D. 2008. The World Bank and Social Transformation in International Politics: Liberalism, Governance, Politics (Abingdon: Routledge)

World Bank. 2016. WorldBank.org, 'Microfinance and Financial Inclusion', available at http://web.worldbank.org/WBSITE/EXTERNAL/NEWS/0, contentMDK:20433592 menuP K:34480 pagePK:64257043 piPK:437376 theSitePK:4607,00.html, accessed on $21^{\text {st }}$ July 2016

World Bank, 1980. Accelerated Development in Sub-Saharan Africa: An Agenda for Action. (Washington DC: World Bank) 